University of South Carolina

Scholar Commons

$1-1992$

\title{
The Influence of Content Development on the Effectiveness of Instruction
}

Judith E. Rink

University of South Carolina - Columbia, jrink@mailbox.sc.edu

Karen E. French

University of South Carolina - Columbia, kfrench@mailbox.sc.edu

Peter H. Werner

Susan Lynn

Florida State University

Amy Mays

Columbia College - Columbia, South Carolina

Follow this and additional works at: https://scholarcommons.sc.edu/pedu_facpub

Part of the Education Commons

\section{Publication Info}

Published in Journal of Teaching in Physical Education, Volume 11, Issue 2, 1992, pages 139-149. http://journals.humankinetics.com/jtpe-contents (C) 1992 by Human Kinetics Publishers, Inc.

This Article is brought to you by the Physical Education, Department of at Scholar Commons. It has been accepted for inclusion in Faculty Publications by an authorized administrator of Scholar Commons. For more information, please contact digres@mailbox.sc.edu. 


\title{
The Influence of Content Development on the Effectiveness of Instruction
}

\author{
Judith E. Rink, Karen E. French, and Peter H. Werner \\ University of South Carolina \\ Susan Lymn \\ Florida State University \\ Amy Mays \\ Columbia College
}

The purpose of this study was to investigate the effect on student learning of different ways of structuring student practice of complex motor skills. Previous research indicated that students who practiced the volleyball set and serve with a four-step progression learned more than students who practiced only the final test for the same number of practice trials; the effect of motivation and practice focused on specific learning cues was unclear. The present study investigated the specific role of progression, refinement, and motivation in learning the volleyball set and serve. Ninth-grade students were randomly assigned to one of five groups: (a) control, (b) final-test practice with refinement tasks after every five trials, (c) final-test practice with motivational feedback only, (d) four-step progression, and (e) four-step progression with refinement after every five trials. All experimental groups were pretested and posttested using the AAHPERD volleyball tests for the set and serve and practiced each skill 10 times a day for 6 days. The results supported the positive effect of providing students with a progression and the need for refinement tasks for parts of the progression.

Practice has long been known to be essential to the acquisition of motor skills. Practice has most often been quantified as a research variable in terms of the number of practice trials or the amount of practice time. The quantity of practice has most often been controlled in motor-learning laboratory research.

J.E. Rink, K.E. French, and P.H. Werner are with the Department of Physical Education at the University of South Carolina, Columbia, SC 29208. S. Lynn is with the Department of Physical Education at Florida State University, Tallahassee, FL 32306. A. Mays is with the Department of Physical Education at Columbia College, Columbia, SC 29203. 
In research on teaching physical education, some measure of practice time or practice trials has been used as a dependent variable in instructional research (Ashy, Lee, \& Landin, 1988; Lee \& Poto, 1988; Phillips \& Carlisle, 1983; Silverman, 1985). Little has been done to investigate relationships between the nature of practice conditions and skill acquisition. Real-world physical education settings usually involve instructional goals related to the acquisition of highly complex motor skills for large numbers of students. In these settings, not only the amount of practice but also the conditions of practice, the focus of that practice, and the manner in which the practice is distributed over lessons are important.

Guidelines for the conduct of practice in learning come from a variety of sources. A major assumption of education and educational psychology is that learning is hierarchical (Fischer, 1980; Gagné, 1968; Rink, 1985; Tyler, 1949; Vogel \& Seefeldt, 1988). In order for students to learn complex skills, they must already possess prerequisite and less complex abilities. Mastery learning is the most structured application of this idea: Skills are broken down into many simpler subtasks to be mastered in order before moving on to more complex tasks. In physical education, mastery learning has been investigated by Blakemore and Roland (1986) and Ashy and Lee (1984). Both studies showed a learning advantage for the mastery groups.

In motor learning literature, investigations into whole versus parts practice have been extensive. Naylor and Briggs (1963), in summarizing the research, have suggested that the decision to practice a skill as a whole or in parts is largely determined by the organization and the complexity of the skill. Skills that are high in complexity (high number of components requiring attention) and low in organization (interrelationships between parts) are better practiced in parts. Skills that have high organization and low complexity are better practiced as a whole.

A major assumption of research on teaching is that time with the content is one of the most significant variables related to student learning. Ideas such as academic learning time, time on task, and practice time are well established in the teacher effectiveness literature (Walberg, 1986). Later studies in the physical education literature have supported the notion that it is not only the amount of practice but also the quality of practice that is related to student learning of motor skills (Silverman, 1985; Werner \& Rink, 1989).

The results of an earlier study on practice conditions for a complex motor skill in a physical education setting suggested that students who received a progression of increasingly difficult tasks performed better on a final test of the volleyball set and serve than did students who merely practiced the final test for the same number of practice trials (French et al., 1991). Two different progression conditions were used in this earlier study: One group was required to reach an $80 \%$ criterion success rate before moving on to the next level, and one group moved on to the next level after a set number of practice trials, regardless of success. There was no difference between these groups. A significant difference was found between the groups that used a progression of increasingly difficult tasks and the group that practiced the final test.

Several alternatives exist to explain why the subjects who practiced with a progression did better than the subjects who practiced only the final test. The first is that students in the final-test group merely became bored and ceased to 
practice with effort. For the higher skilled students in particular, this idea is supported by practice profiles that showed a beginning trend toward progress and then a rapid decline in improvement after a few days of practice. For the low-skilled student, little success was achieved, but practice profiles showed more continuous progress. A second possible explanation is that a change in the practice conditions of the task forced students to continue to process critical task information with each practice trial, leading to enhanced learning. This is similar to explanations for contextual interference proposed by Lee and Magill (1983), who suggested that repeated practice of the same skill with no variability produces lower rates of learning (Del Rey, 1989; Goode \& Magill, 1986). Variability in practice causes a higher level of processing and, therefore, greater learning.

A third explanation is that the final test was just too difficult to be mastered as a whole, and subjects needed to work on smaller parts of the task before they could benefit from practicing the whole. This idea is commonly referred to as the progressive-part method. The advantage of this method is that it restricts the attention demands of the learner (Magill, 1989). Many of these explanations may interact with each other in real-world settings.

If increased processing in practice is the critical variable in whether or not a student learns a motor skill, a teacher should be able to facilitate an increased level of student processing in several ways. First, the teacher can increase learner motivation, thereby increasing attention and effort. Second, the teacher can change task conditions, thereby eliminating repetitive practice and increasing attention. Third, the teacher can narrow and focus the learner's attention on particular performance aspects without changing the conditions of practice.

Rink (1985) described the movement task that changed conditions of practice as an extension task. Extension tasks manipulate the difficulty or complexity of a motor skill objective during a lesson by changing the conditions or the focus of intent of the task. Tasks that focus a group of learners on an aspect of performance (the process) without changing the conditions of the task are described as refining tasks (e.g., "Get your toss to the side and in front of your body"). Tasks that focus the student on how to use movement in competitive ways are described as application tasks.

Rink (1985) referred to the process a teacher uses to develop content through movement tasks that manipulate task demands as content development. Although evidence exists to support the idea that the use of extension, refinement, and application tasks in physical education lessons does effect the amount of student learning (Gusthart \& Sprigings, 1989; Masser, 1987; Werner \& Rink, 1989); little has been done to investigate the nature of this process.

The purpose of this study was to investigate the effect on student learning of structuring student practice of complex motor skills in different ways. Four groups practiced the volleyball set and serve for a given number of trials. One group practiced the final test for both skills and received only motivational statements concerning their performance (motivation group). A second group practiced the final test with the teacher refocusing the students on an aspect of their performance that needed refinement after every five trials (refinement group). A third group practiced a four-step progression ordered from simple to complex (extension group), and a fourth group practiced the same progression with the addition of refining tasks after every five trials of each step of the progression 
(combination group). These groups allowed the separation of the motivational effects on learning from the specific influences of extension (progression), refinement, and the combined processes.

The learning environment was kept as ecologically valid as possible. Subjects participated as part of their normal physical education class. Normal attendance and warm-up procedures were maintained. Subjects met with their lead teacher following class warm-up for each day's instructions. Number of practice trials, pretest and posttest protocols, and the specific progressions used in the first study were maintained in this second study for comparative purposes (French et al., 1991).

\section{Methods}

\section{Subjects}

Students $(N=59)$ from coeducational physical education classes in a local public high school served as subjects in the practice interventions. Students from an additional physical education class $(N=17)$ were randomly selected as a control group. The majority of subjects were in the ninth grade.

\section{Procedures}

All subjects were pretested on the overhead set and serve tests from the AAHPERD (1967) Volleyball Skill Test Manual, which also served as the final tests. The overhead-set test required students to receive a ball tossed from the center of the court and send it either right or left over an 8-foot rope to a $6 \times 10$ foot target area. Each subject received 10 balls for each side and 1 point for each set that went over the rope and landed in the target area. The overhead-serve test required subjects to serve a legal ball across the net into a marked court. Subjects received 1-4 points for each of 10 trials depending on where the ball hit the ground within the court.

Control subjects participated in their regular physical education class (not volleyball). The remaining subjects were randomly assigned to one of the four practice groups. Each group had 14 or 15 subjects evenly divided by gender.

The conditions for each of the four treatment groups are described in Table 1. Two groups practiced only the final test. The motivation group practiced the final tests each day and received a great deal of reinforcement (cheerleading, verbal praise, tokens) for their effort but no specific information on their performance. The refinement group also practiced the final tests each day. After every five trials of a skill, the teacher selected a performance cue as a group practice focus for the next set of trials.

Two groups practiced a preset four-step progression for each skill (Table 2). The teacher presented a predetermined set of cues and demonstrated each task to the learners before the onset of practice of each step of the progression. The extension group received a task presentation on each step of the progression only; no additional information was given. The combination group received the same task presentation plus a focused refinement task after every five trials of practice. Subjects in these two groups performed 10 trials of each skill each day for 6 days, a total of 60 practice trials for each skill. Both groups practiced the first and second levels of the progression for 1 day each (Day 1 and Day 2) and the third and fourth levels of the progression for 2 days each (Days 3 and 4, and Days 5 and 6). 
Table 1

Treatment Groups and Practice Conditions

Group Condition

Motivation 60 trials of final test over 6 days; continuous motivating feedback on effort only

Refinement 60 trials of final test over 6 days; refinement task after every five trials

Extension $\quad 60$ trials of each skill ( 1 day at Levels 1 and 2 and 2 days at Levels 3 and 4 of the progression)

Combination 60 trials of each skill ( 1 day at Levels 1 and 2 and 2 days at Levels 3 and 4 of the progression); refinement task after every five trials

Table 2

Serve and Set Progressions

$\begin{array}{lll}\text { Skill } & \text { Level } & \\ \text { Serve } & 1 & \text { Task } \\ & 2 & \text { Stand 10 feet from a wall and hit over an 8-foot line on the wall } \\ & 3 & \text { Serve over the net from behind the baseline } \\ \text { Set } & 4 & \text { AAHPERD volleyball serve test } \\ & 1 & \text { Self-toss and move into correct setting position } \\ & 3 & \text { Set the ball over a 10-foot rope from a partner's toss } \\ & 3 & \text { Set the ball to the left or right over an 8-foot rope } \\ & 4 & \text { AAHPERD volleyball test for the set }\end{array}$

To ensure that all groups had an initial cognitive understanding of the serve and set pattern before beginning practice, subjects were given instruction on each pattern before they were divided into groups, and they were required to physically demonstrate the pattern without the ball. All practice was conducted in the high school gymnasiums using four modified volleyball courts for the set practice and two regulation-size courts for the serve. Two teachers were assigned to each practice group. Students worked primarily in partners, with 1 student practicing and 1 student recording the result of each practice attempt. Enough regulationsize balls were available to allow each student to either be practicing or recording.

A lead teacher did all the task presentations, which were standardized across groups. In a previous study with the same teachers, no significant effect for teacher was found (French, Rink, \& Werner, 1987). The teachers' role during practice was primarily that of monitoring students' turn taking and their recording of practice attempts. Individual feedback was very limited. Audiotapes of all lessons, teacher plans, and teacher notes following lessons were kept to confirm the treatment. No evidence of differences in process other than the designated 
treatment were found in reviewing these materials. No systematic observation tools were deemed necessary to confirm treatment. All students, including the control group, were posttested on Day 7.

\section{Results}

The skill level of each subject was operationally defined on the basis of the subject's pretest score. Average skill in the serve and set was defined as a pretest score above 5; low skill in the serve and set was defined as a score equal to or below 5 . The scores of the serve and set were analyzed in separate $5 \times 2 \times 2$ (Practice group $\times$ Skill level $\times$ Pretest-posttest) ANOVAs with repeated measures on the last factor. The analysis for the set revealed significant effects for Group, $\quad F(4,71)=3.61, \quad p<.01 ; \quad$ Skill level, $\quad F(1,65)=117.77, \quad p<.01$; Group $\times$ Pre-post, $F(4,65)=3.64, p<.01$; and Group $\times$ Skill level $\times$ Pre-post, $F(5,65)=4.05, p<.01$. The results of the ANOVA for the serve indicated significant effects for Skill, $F(1,66)=341.75, p<.01$; Pre-post, $F(1,66)=19.84, p<.01$; and Group $\times$ Pre-post, $F(4,66)=3.09, p<.03$. The Group $\times$ Skill $\times$ Pre-post interaction approached significance, $F(5,66)=2.14, p<.07$.

The significant main effects and two-way interaction were superceded by the three-way interaction of group, skill level, and pre-post that was significant for the set, and the same trend was indicated for the serve. Average-skilled students in the control group regressed from pretest to posttest in the set. Slight improvement was made by the low-skilled students in the control group with the set and by the low- and average-skilled students in this group with the serve.

Figure 1 describes the pretest and posttest scores for the average- and lowskilled students in the experimental groups. The average-skilled subjects in the combination group showed great improvement in the posttest performance for the serve. Those in the control and motivation groups improved slightly, those in the extension group remained constant, and those in the refinement group regressed. The low-skilled subjects in all groups improved their serve slightly; however, those in the combination and refinement groups appeared to have improved the most.

The average-skilled subjects in the combination group improved the most in the set. Those in the extension group remained relatively unchanged, and those in the motivation and refinement groups regressed. The low-skilled students in all groups improved slightly, with those in the combination group exhibiting slightly greater improvement that those in the other groups.

Profiles of success rates during acquisition were created for average- and low-skilled students in the experimental groups. The scores for each practice day were converted to percentages for each group by dividing the student's score by the total possible points for that particular task. The percentages were averaged for each skill level within a group. Figures $2,3,4$, and 5 show the success rate across practice in the serve and set for the low- and average-skilled subjects in each group.

Patterns of success rates were compared for the groups that practiced the final tests only and the groups that practiced with a progression. The patterns for both groups that practiced the final tests (refinement and motivation groups) are similar for both the low- and average-skilled students practicing the set and the 


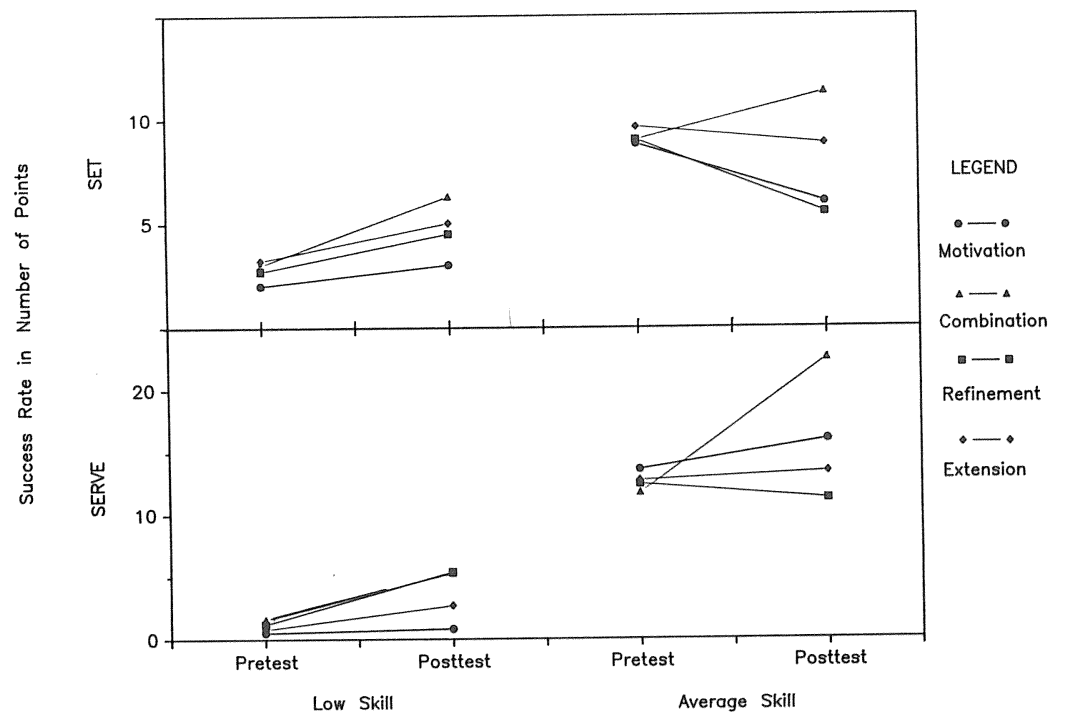

Figure 1 - Pretest and posttest means for the average- and low-skilled students in each group.

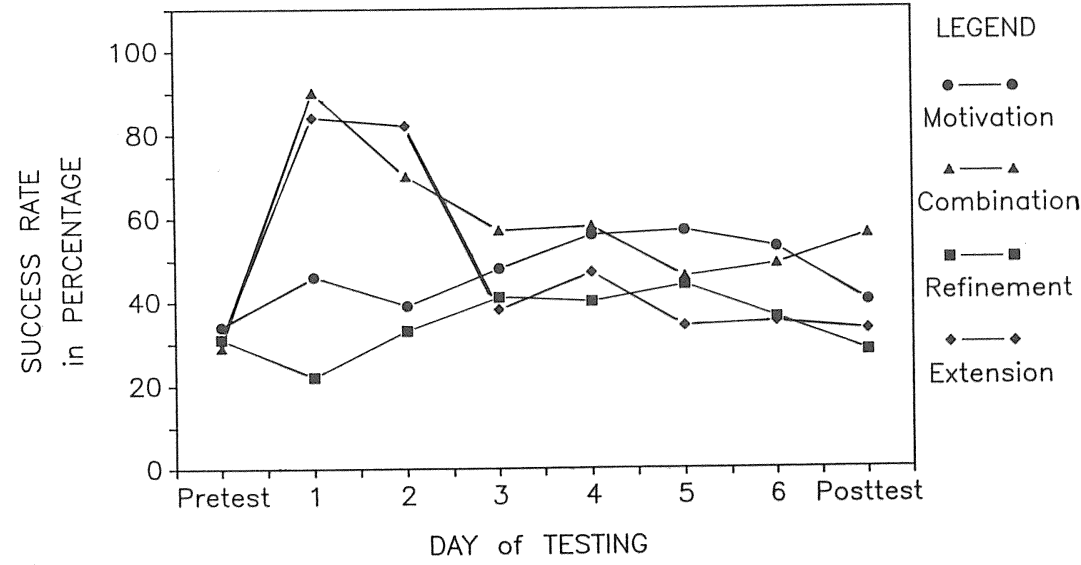

Figure 2 - Profiles of success rates across practice in the serve-average skill.

average-skilled students practicing the serve. The low-skilled students in the refinement group made greater progress with the serve than did the low-skilled students in the motivation group. The patterns for both groups that used a progression of tasks (progression and combination groups) are similar at early levels of the set progression for the average-skilled students. The low-skilled students in the combination group were more successful in the early stages of the serve progression than were those in the group that had extension tasks alone. As 


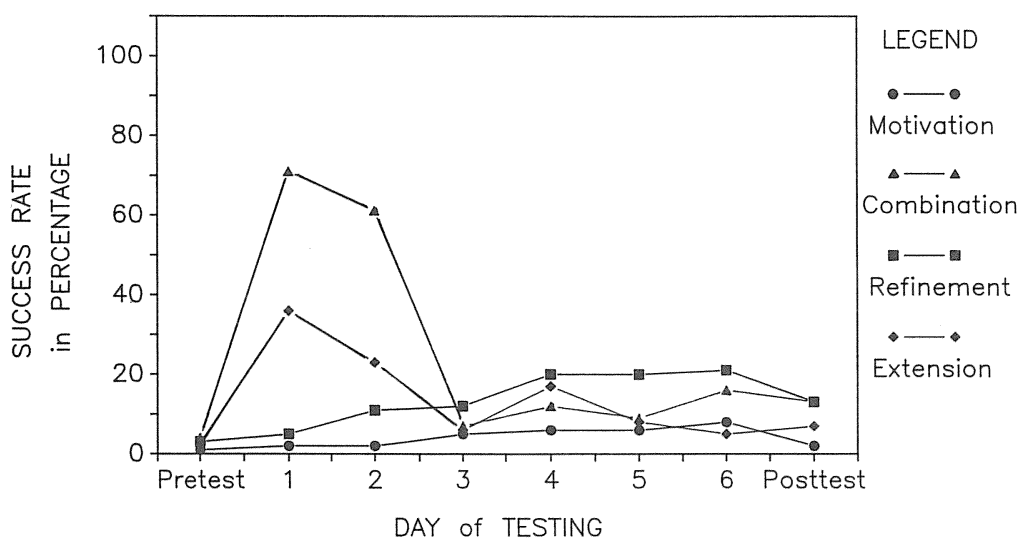

Figure 3 - Profiles of success rates across practice in the serve-low skill.

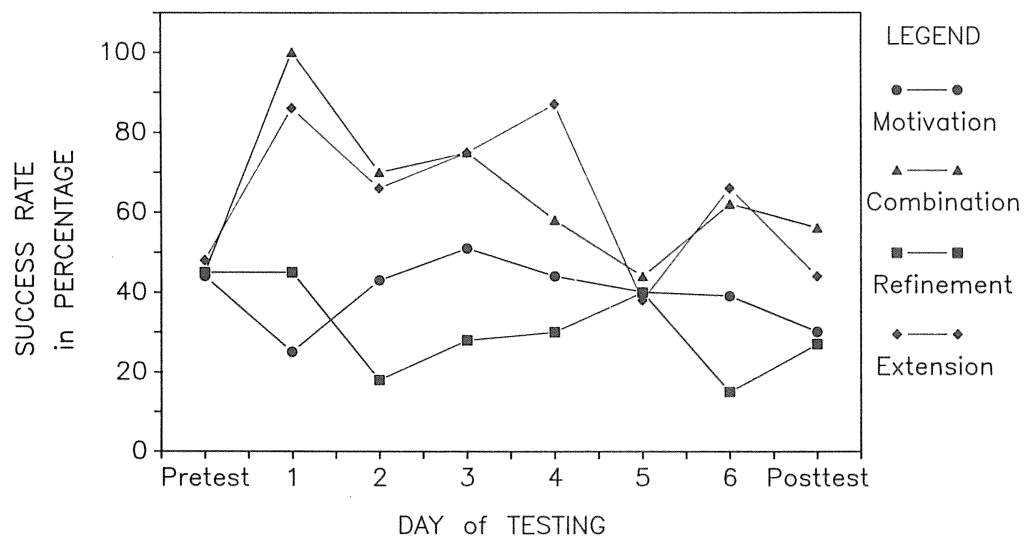

Figure 4 - Profiles of success rates across practice in the set-average skill.

the difficulty of the task increased in the later stages of the progressions, the combination group had higher success levels and seemed to maintain that advantage thereafter.

\section{Discussion}

Several issues relative to the results of this study deserve exploration. The first is the effect of progression versus practice of the final test alone. The second is differences between just changing the conditions of the task (extension) and adding refining information throughout practice for the learner. The third is the response of the low-skilled learner to these manipulations.

Many physical educators would say that the group that received the most practice with the final test would be the group that achieved the most. The results of this study, as well as the results of the previous study, do not support practice 


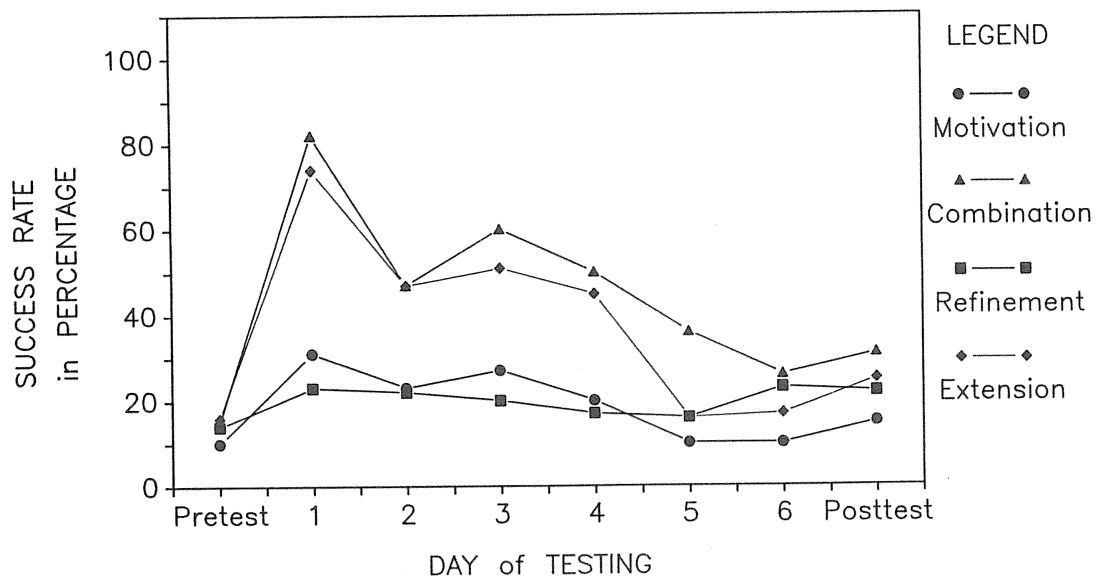

Figure 5 - Profiles of success rates across practice in the set-low skill.

of the final test. Alternative explanations exist for this finding. One of the strongest explanations is, of course, that the volleyball set and serve are complex motor skills that need to be reduced at early stages of learning to allow the individual to better process task demands. The results of this study support this idea. The motivation group that practiced the final test in this study was highly motivated and affectively very positive toward what they were doing. The addition of a high level of motivation to the practice of the final test did not change the results of the first study (French et al., 1991), which demonstrated the superiority of a progression over practice of the final test. However, task complexity cannot be the only explanation for the lack of success in the final-test group. If it were, there should have been a difference between how low- and average-skilled students performed in the groups practicing the final test. There was not. The averageskilled students did not improve more than the low-skilled students. The lowskilled student did profit from refinement tasks while practicing the final test, but the result was not significant.

The progression condition present in both the extension and combination groups seemed to facilitate a higher success rate and a higher level of retention in a way that practice of the final test alone could not. If contextual interference (Lee \& Magill, 1983) is part of the explanation, if changing the conditions of the task caused students to process what they were doing more than not changing the task, then it should not make a difference how you change the practice conditions. If the nature of the progression itself is what is important, then how you create a whole-part-whole learning sequence is relevant. Because this study used a consistent prearranged progression for both groups, it can only be hypothesized that not only a progression but also the nature of that progression relative to specific content will effect the acquisition of motor skills in physical education settings.

Another interesting result of this study was the difference between the group that practiced a progression (extension group) and the combination group, which also practiced the progression but added refining tasks. The success profiles of both groups reveal that there might be specific tasks in the progression 
for which the student needed additional information. The most clear example of this was the point in the practice of the volleyball set where students had to receive the ball from one direction and send it to another (Task 3, Days 3 and 4). The combination group had a much greater success rate at this point than the extension group had and maintained this advantage through the remaining tasks and the posttest. The results of this study might suggest that changing task conditions alone is effective unless the student is not able to make necessary adjustments to the new conditions and needs teacher cuing following the initial practice of the task.

From a very practical perspective, it must be pointed out that there were students in this study who made no progress from the pretest to the posttest. They had little success once the serve progression asked them to get the ball over the net, even from half court. These results are consistent with the results of the previous study. Some interesting observations on the low-skilled student are important to mention. The low-skilled students in all of the groups were motivated. Although it is clear that the volleyball overhead serve and set were not appropriate skills for these students, more progress was made when students were given refinement information in the serve and when the set included a progression. It is not clear whether these students would have achieved more with additional practice time or whether an altogether different instructional objective, focusing on a prerequisite skill, would have been more appropriate.

\section{References}

AAHPERD. (1967). Volleyball skills test manual. Reston, VA: Author.

Ashy, M.H., \& Lee, A.M. (1984, March). Effects of mastery learning on throwing accuracy technique. Paper presented at the annual conference of the American Alliance for Health, Physical Education, Recreation and Dance, Anaheim, CA.

Ashy, M.H., Lee, A.M., \& Landin, D.K. (1988). Relationship of practice using correct technique to achievement in a motor skill. Journal of Teaching in Physical Education, 7, 115-120.

Blakemore, C.L., \& Roland, P. (1986, April). A comparison of achievement of students taught psychomotor skill using mastery learning, non-mastery, and no drills methods. Paper presented at the annual conference of the American Alliance for Health, Physical Education, Recreation and Dance, Cincinnati, $\mathrm{OH}$.

Del Rey, P. (1989). Training and contextual interference effects on memory and transfer. Research Quarterly for Exercise and Sport, 60, 342-347.

Fischer, K.W. (1980). A theory of cognitive development: The control and construction of hierarchies of skill. Psychological Review, 87, 477-531.

French, K.E., Rink, J.E., Rickard, L., Mays, A., Lynn, S., \& Werner, P.H. (1991). The effects of practice progressions on learning two volleyball skills. Journal of Teaching in Physical Education, 10, 261-274.

French, K.E., Rink, J.E., \& Werner, P.H. (1987). The effects of contextual interference on the retention of three volleyball skills. Perceptual and Motor Skills, 71, 179186.

Gagné, R. (1968). Contributions of learning to human development. Psychological Review, 75, 177-191.

Goode, S., \& Magill, R.A. (1986). The contextual interference effects in learning of three badminton serves. Research Quarterly for Exercise and Sport, 57, 308-314. 
Gusthart, J.L., \& Sprigings, E.J. (1989). Student learning as a measure of teacher effectiveness. Journal of Teaching in Physical Education, 8, 298-311.

Lee, T.D., \& Magill, R.A. (1983). The locus of contextual interference in motor skill acquisition. Journal of Experimental Psychology: Learning, Memory and Cognition, 9, 730-746.

Lee, A.M., \& Poto, C. (1988). Instructional time in physical education: Contribution and current issues. Quest, 40, 63-73.

Magill, R.A. (1989). Motor learning concepts and applications. Dubuque, IA: Wm. C. Brown.

Masser, L. (1987). The effect of refinement on student achievement in a fundamental motor skill in grades K-6. Journal of Teaching in Physical Education, 6, 174-181.

Naylor, J., \& Briggs, G. (1963). Effects of task complexity and task organization on the relative efficiency of part and whole training methods. Journal of Experimental Psychology, 65, 217-244.

Phillips, D., \& Carlisle, C. (1983). A comparison of physical education teachers characterized as most and least effective. Journal of Teaching in Physical Education, 2(3), 55-67.

Rink, J.E. (1985). Teaching physical education for learning. St. Louis, MO: Times Mirror Mosby.

Rink, J.E., French, K.E., Werner, P.H., Rikard, L., Lynn, S.K., \& Mays, A.M. (1989, February). The influence of practice progression on the effectiveness of instruction. Paper presented at the Southern District of AAHPERD, Chattanooga, TN.

Silverman, S. (1985). Relationships of engagement and practice trials to student achievement. Journal of Teaching in Physical Education, 5, 13-21.

Tyler, R. (1949). Basic principles of curriculum and instruction. Chicago: The University of Chicago Press.

Vogel, P., \& Seefeldt, V. (1988). Program design in physical education. Indianapolis: Benchmark Press.

Walberg, H. (1986). Synthesis of research on teaching. In M. Wittrock (Ed.), Handbook of research on teaching (3rd ed., pp. 214-229). New York: Macmillan.

Werner, P.H., \& Rink, J.E. (1989). Case studies of teacher effectiveness in second grade physical education. Journal of Teaching in Physical Education, 8, 280-297. 